\title{
INFLUENCE OF TRAILING EDGE TAB ON MOMENT CHARACTERISTICS OF NACA 23012 AIRFOIL
}

\author{
E. Lasauskas ${ }^{1)}$, Th. Lutz ${ }^{2)}$, M. Dietz ${ }^{2)}$ \\ ${ }^{1)}$ Antanas Gustaitis Aviation Institute of Vilnius Gediminas Technical University, LT-02187 Vilnius, Lithuania. \\ E-mail: edulas@ai.vgtu.lt \\ ${ }^{2)}$ Institute of Aerodynamics and Gas Dynamics, Universität Stuttgart, D-70550 Stuttgart, Germany. \\ Received 04 May 2007, accepted 10 Oct 2007
}
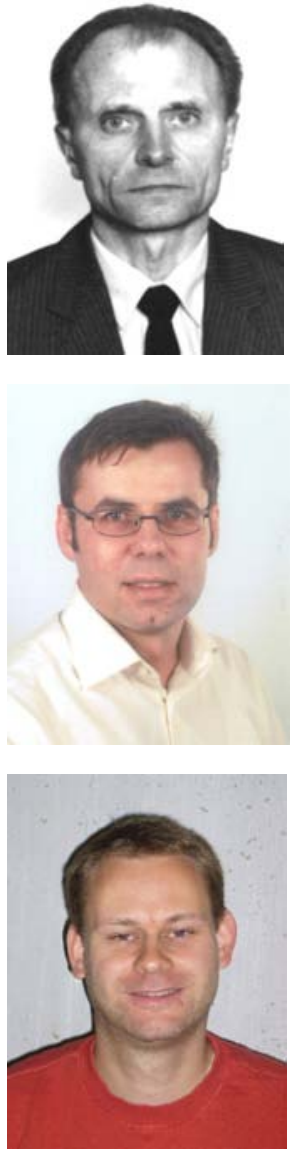

Eduardas LASAUSKAS, Assoc Prof

Eduacation: 1976 - diploma degree in Aircraft Mechanical Engineering, Kazan Aircraft Institute, 2000 - doctoral degree in Mechanical Engineering, Vilnius Gediminas Technical University.

Professional experience: March 1976 - July 1998 aerodynamics engineer at joint stock company Sportine aviacija.

Research interest: low speed wing aerodynamics.

Professional membership: member of Organisation Scientifique et Technique du Vol a Voile (OSTIV).

Teaching: aerodynamics, flight dynamics.

Present position: associate professor in the Department of Aviation Mechanics at the Antanas Gustaitis Aviation Institute of Vilnius Gediminas Technical University.

Thorsten LUTZ, Dr Eng

Eduacation: 1991 - diploma degree in Aerospace Engineering, Universität Stuttgart, 1999 - doctoral degree in Aerospace Engineering, Universität Stuttgart.

Professional experience: Institute of Aerodynamics and Gas Dynamics, Universität Stuttgart

Research interest: subsonic and transonic aerodynamics, airfoil design and optimisation.

Professional membership: chairmen of the DGLR Committee S2.3 Aviation Systems Lighter Than Air, member of the Luftahrttechnisches Handbuch Committee, since 5-2004.

Teaching: Aircraft aerodynamics I and II, airfoil design.

Present position: lecturer, branch chief of Aircraft Aerodynamics, Institute of Aerodynamics and Gas Dynamics, Universität Stuttgart.

\section{Markus DIETZ, Dipl Eng}

Education: 2003 - diploma degree in Aerospace Engineering, Universität Stuttgart.

Research interest: helicopter aerodynamics and structural dynamics, fluid and structure coupling, CFD.

Present position: scientific employee at Institute of Aerodynamics and Gas Dynamics, Universität Stuttgart.

Abstract. A comparison of predicted and measured aerodynamic characteristics of the original NACA 23012 airfoil and an airfoil with a trailing edge tab is presented. XFOIL code is used for prediction. It is shown that the modification of the airfoils only on the upper side at the trailing edge affects practically only moment characteristics. An example of the airfoil modification with zero moment coefficients is presented.

Key words: airfoil, trailing edge tab, moment characteristics.

\section{Introduction}

Small changes in geometry near the trailing edge can make significant changes in pressure distribution and result in significant changes in the integral characteristics of an airfoil. One example of such trailing edge devices is a trailing edge tab (G. Reichert, S.N. Wagner, Fig 26). The trailing edge of the airfoil is the tab parallel to the chord, figure 1 . 
The modified profile has compared to the original NACA 23012 sections shape a slightly larger lift curve slope and a negative moment curve slope, whereas the original profile has a positive moment curve slope. The moment curve slope is very important for the damping characteristics and loads of helicopter blades.

\section{Comparison of calculated and measured data}

To check the possibility of predicting the influences of such a trailing edge tab, calculations were carried out using XFOIL, an interactive program for the design and analysis of airfoils [1]. The Reynolds number and turbulence level of the experiment are not presented in the article [2]. The Reynolds number and amplification ratio was varied to achieve good comparison of calculated and measured drag polar. Figure 2 shows the comparison of calculated and measured data of the original NACA 23012 airfoil and an airfoil with a trailing edge tab (long tab) at $\operatorname{Re} 2.0 \cdot 10^{6}$ and $n=0.1$ full turbulence flow. The calculation accurately predicts the influence of the trailing edge tab on the moment coefficient curve.
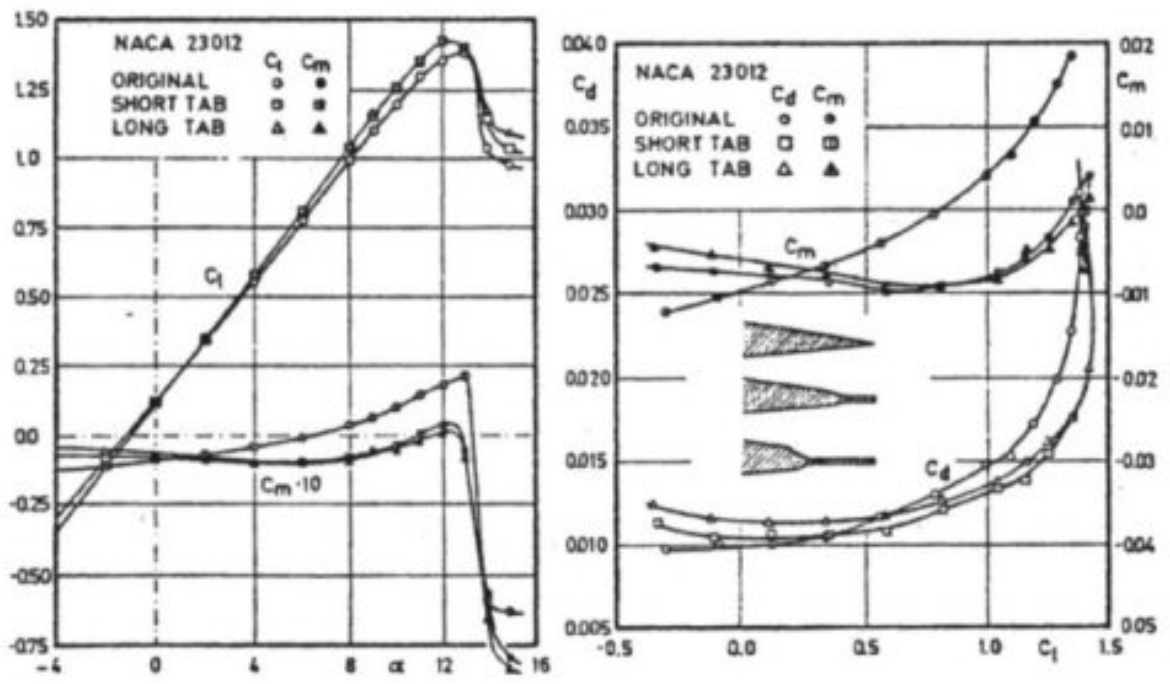

Fig 1. Effect of trailing edge tab on characteristics of NACA 23012 profile at $M=0.4$ [2]

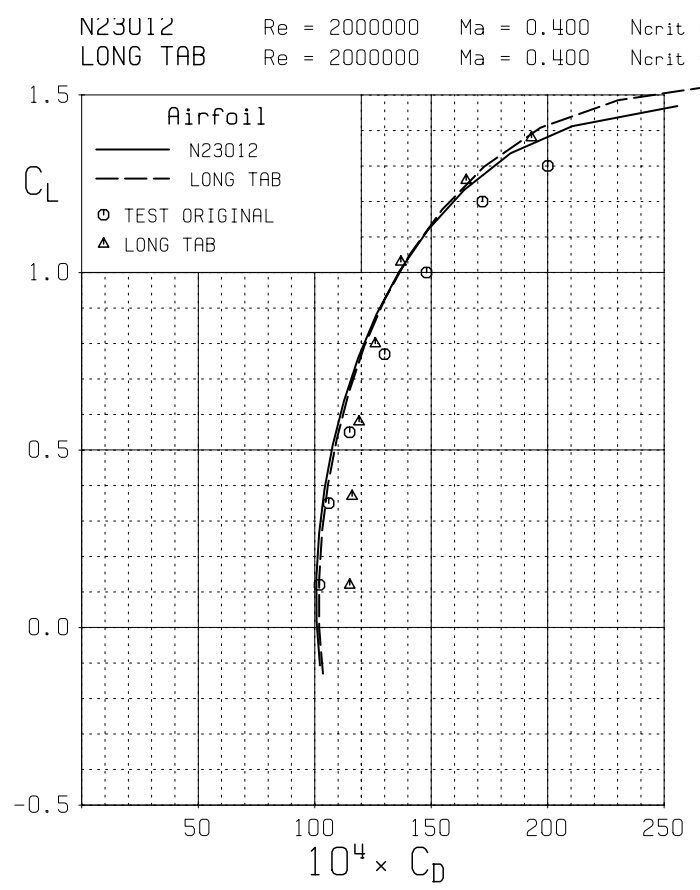

0.100
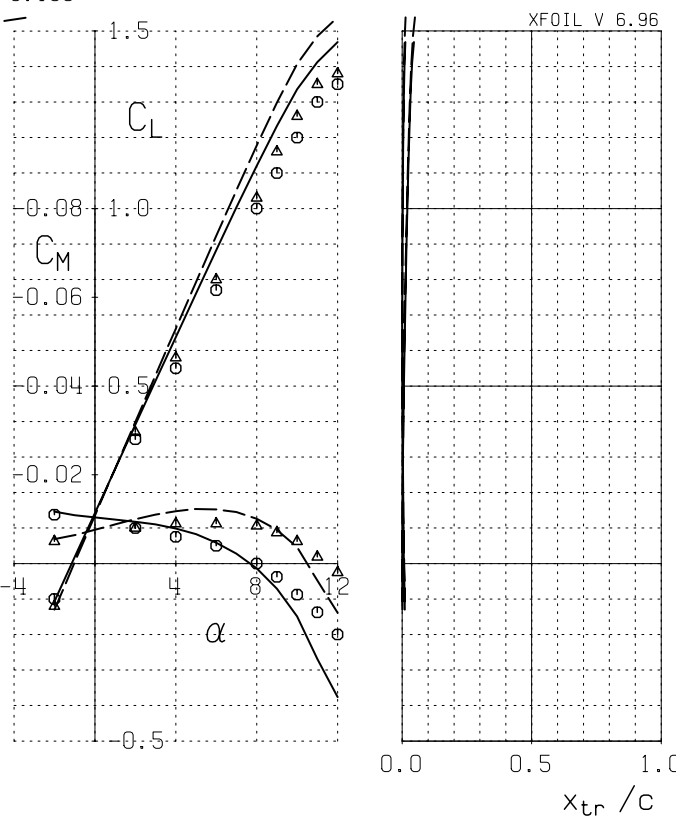

\section{ORIGINAL}

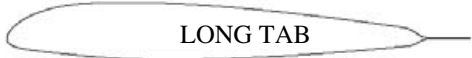

Fig 2. Comparison of calculated and measured data of original NACA 23012 airfoil and airfoil with trailing edge tab 


\section{Calculation of influence of modification near trailing edge on airfoil characteristics}

Figure 3 shows the distribution of the pressure coefficient over the original airfoil and over the airfoil with the long tab at zero angle of attack. The tab affects the pressure distribution only in the region of the tab. There is a steep increase in pressure at the beginning of the tab. Figure 4 shows the friction coefficient distribution along the original airfoil and the airfoil with the tab. At the beginning of the tab, where drag rises, the friction coefficient drops, but it is still positive. This means that the boundary layer remains attached. That is why the integral boundary layer model captures the effect of the tab on the moment characteristics of the airfoil [1].
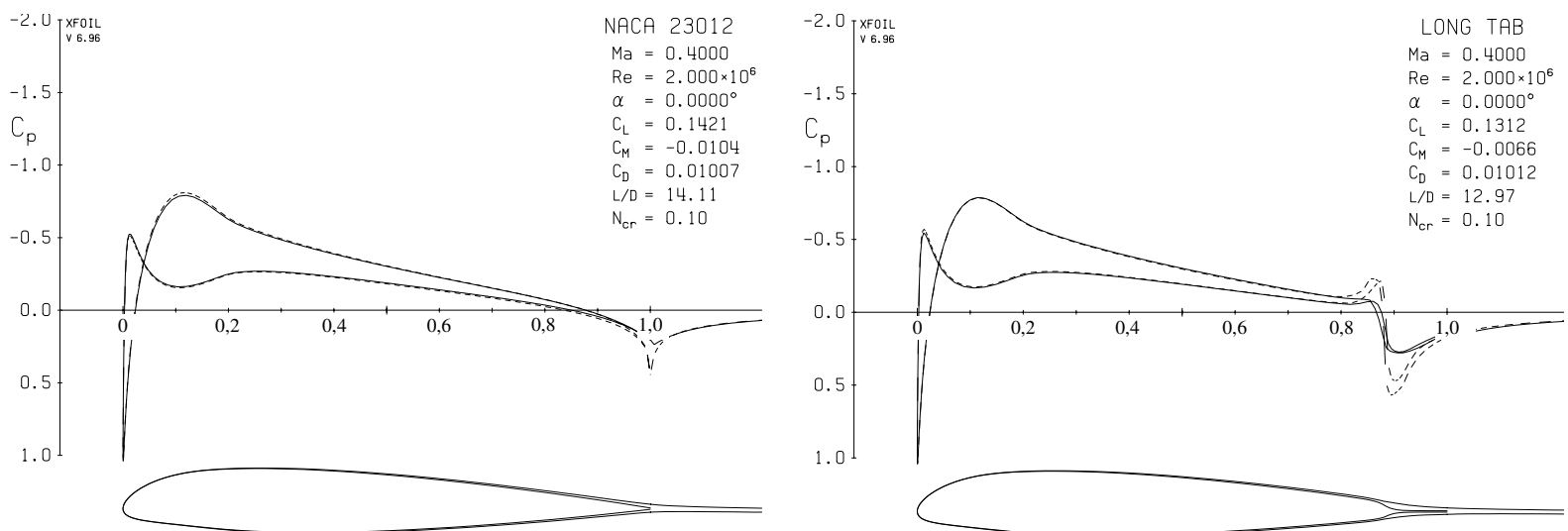

Fig 3. Distribution of pressure coefficient over original airfoil and airfoil with trailing edge tab at zero angle of attack
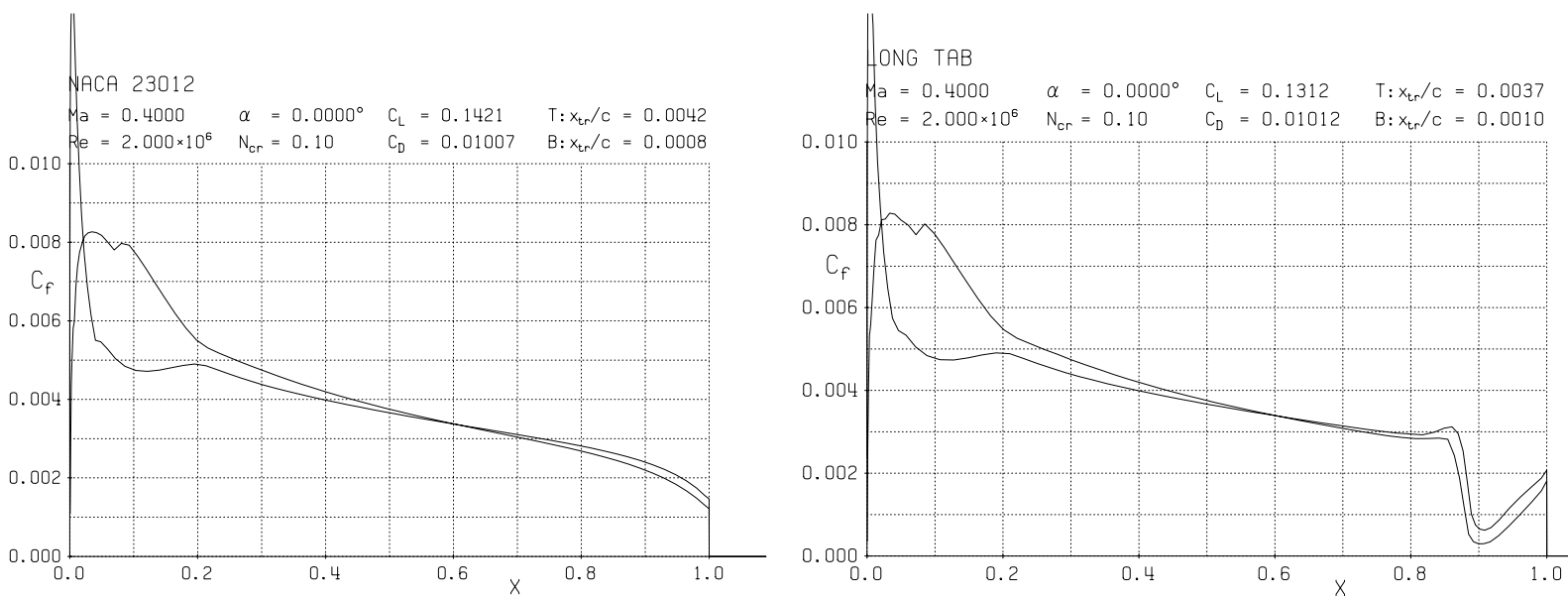

Fig 4. Distribution of friction coefficient over original airfoil and airfoil with trailing edge tab at zero angle of attack

The influence of airfoil modification on the upper and lower side on the moment characteristics was calculated separately. Figure 5 shows the moment curves of four variants. The first curve is for the original NACA 23012 airfoil. The second curve corresponds to airfoil modification near the trailing edge on the lower side. This modification changes the camber of the airfoil near the trailing edge and the moment coefficient is more negative at all angles of attack.

Most interesting is the modification on the upper side, the third curve in figure 5. The biggest influence of this modification occurs at low angles of attack, and there is no influence at high angles of attack. The reason for such behaviour is that the modified part on the upper side is in the separated region at high angles of attack.
Figure 6 shows the pressure distribution of the original airfoil and the airfoil with the upper tab on the upper side at zero angle of attack. The pressure is different on the upper side near the trailing edge. Due to the decambering effect, the pressure distributions on the upper and lower side intersect, causing a down force in the vicinity of the trailing edge. That is why the moment coefficient is different at this angle of attack. 

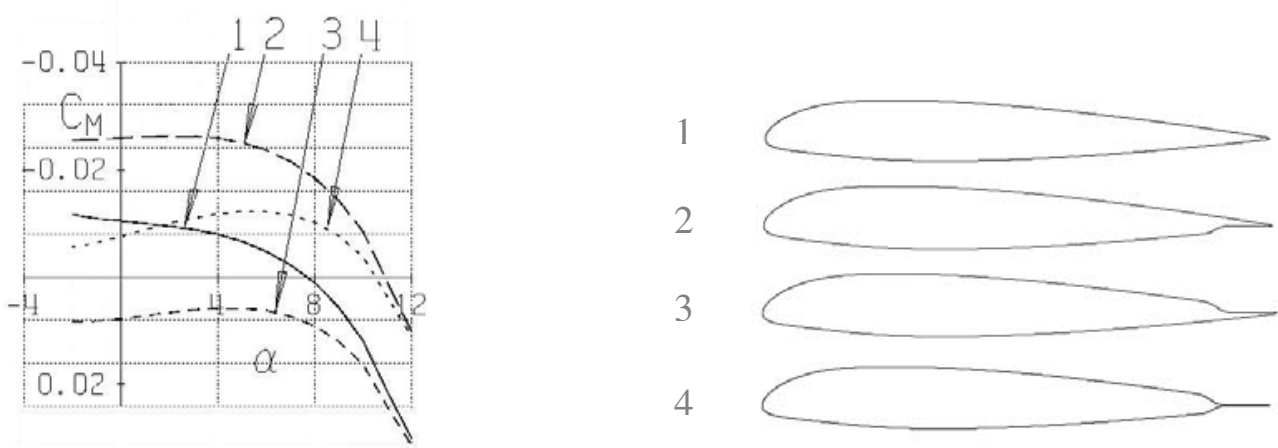

Fig 5. Influence of NACA 23012 airfoil modification on upper and lower side on moment characteristics (calculation XFOIL, $R e=2 \cdot 10^{6}$, full turbulence)
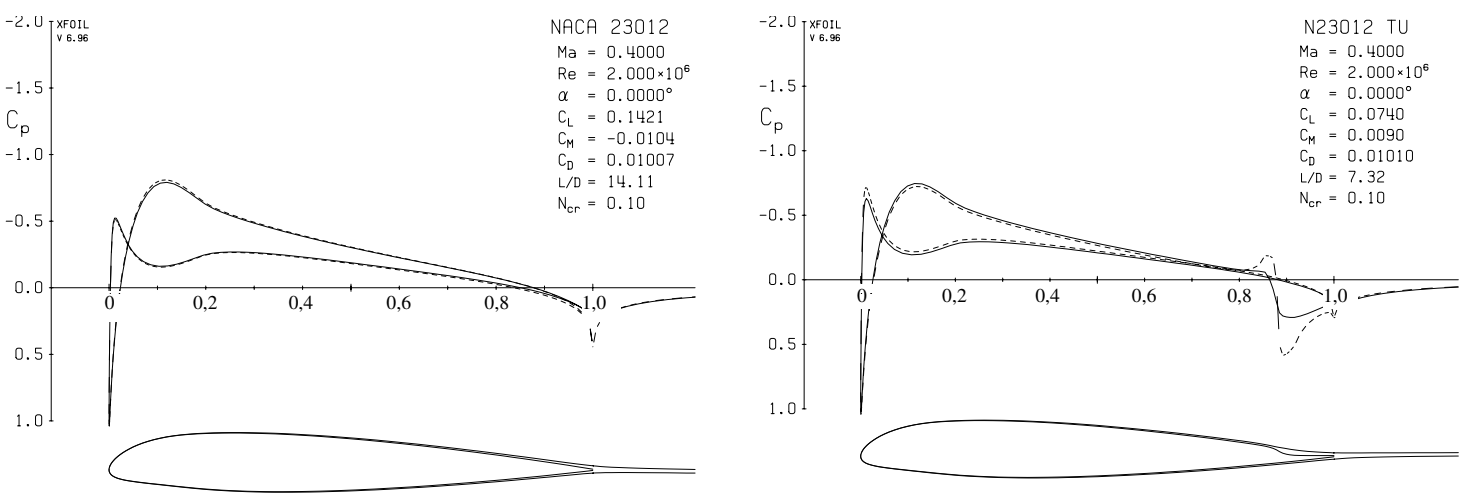

Fig 6. Distribution of pressure coefficient over original airfoil and airfoil with upper tab at zero angle of attack
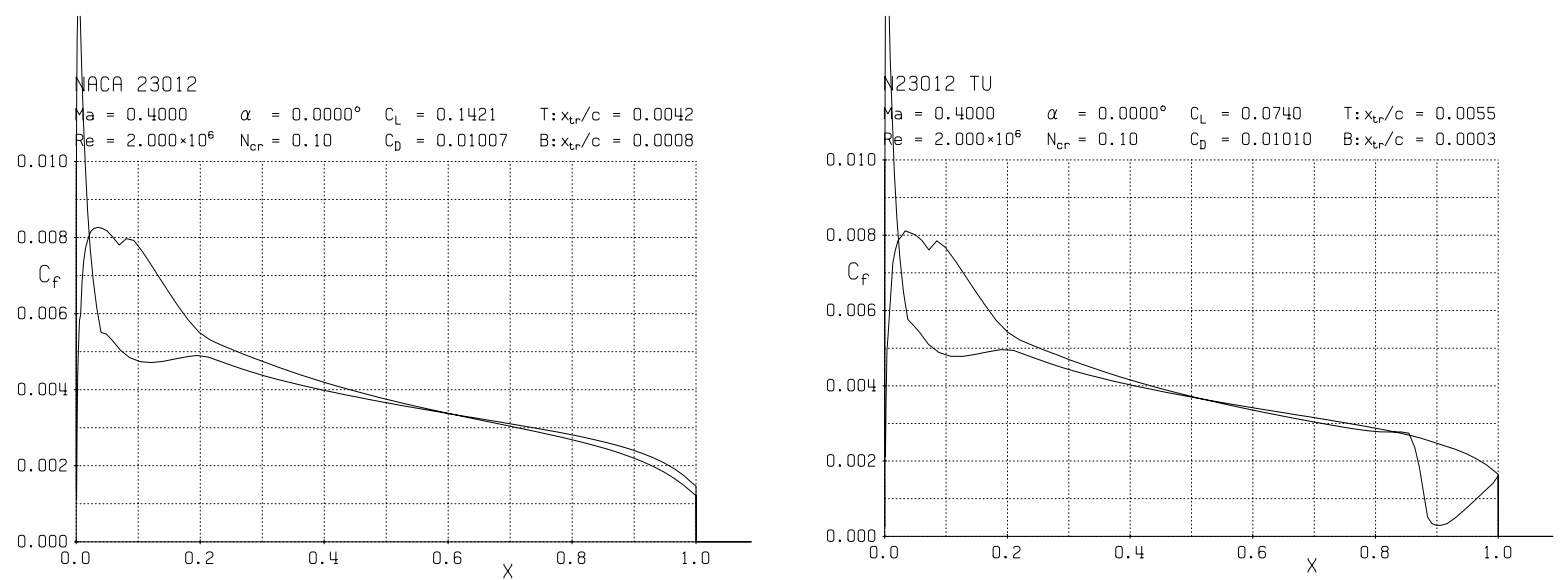

Fig 7. Distribution of friction coefficient over original airfoil and airfoil with upper tab at zero angle of attack

Figure 7 shows the distribution of the friction coefficient along the original airfoil and the airfoil with the upper tab. At the beginning of the tab, where drag rises, the friction coefficient drops, but it is still positive. This means that the boundary layer remains attached.

Figure 8 shows the pressure distribution of the original airfoil and the modified airfoil on the upper side at a $12^{\circ}$ angle of attack. The modified part of the airfoil is now in the region of separated flow. Pressure distribution is nearly the same on both airfoils. The moment coefficient and even lift is the same for both airfoils at high angle of attack.
It is therefore possible to control the slope of the moment coefficient curve with shape modification on the upper side near the trailing edge.

An example is in figure 9, which compares calculated data of the original NACA 23012 airfoil and an airfoil with a modification on the upper side near the trailing edge that gives a zero moment coefficient. The difference is in the moment coefficient curve at low angles of attack when the moment coefficient is nearly zero. The lift curve is practically the same. The lift curve slope is slightly higher. 

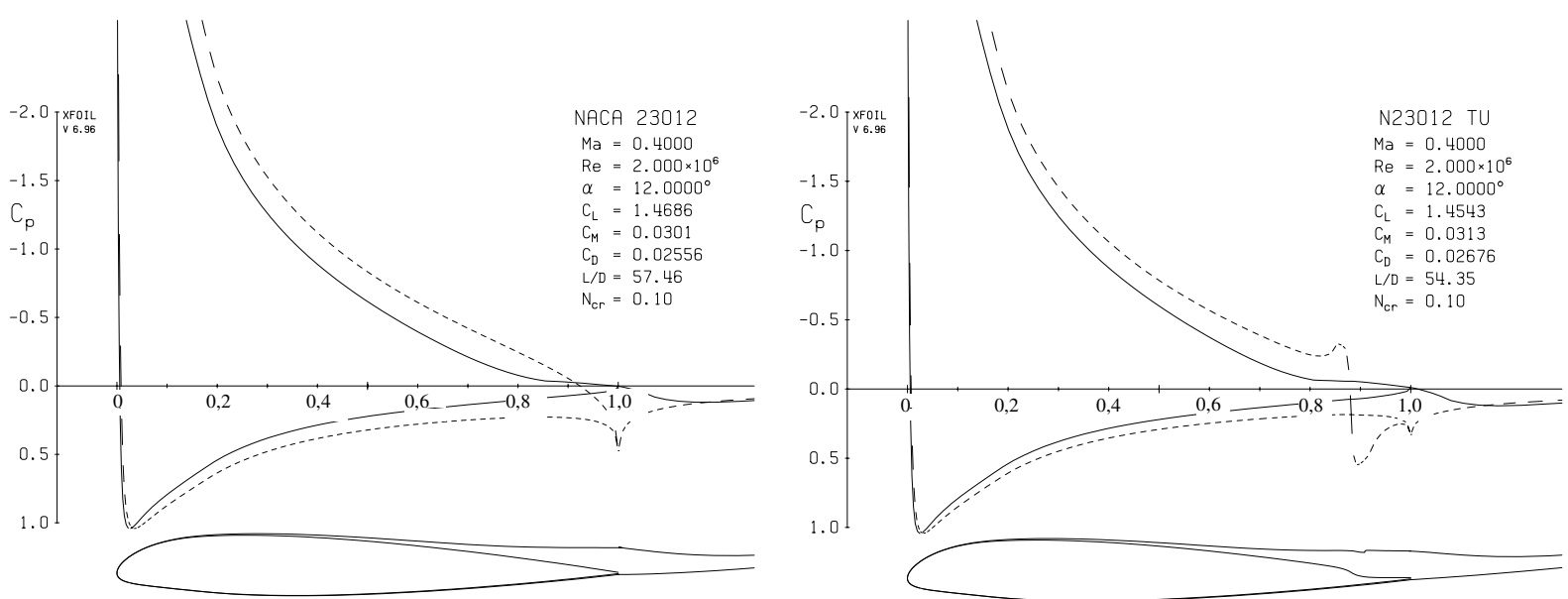

Fig 8. Distribution of pressure coefficient over original airfoil and airfoil with upper tab at $12^{\circ}$ angle of attack

$$
\begin{array}{llll}
\text { N23U12 } & R e=2000000 & M a=0.400 & \text { Ncrit }=0.100 \\
\text { N23012mod } & R e=2000000 & M a=0.400 & \text { Ncrit }=0.100
\end{array}
$$
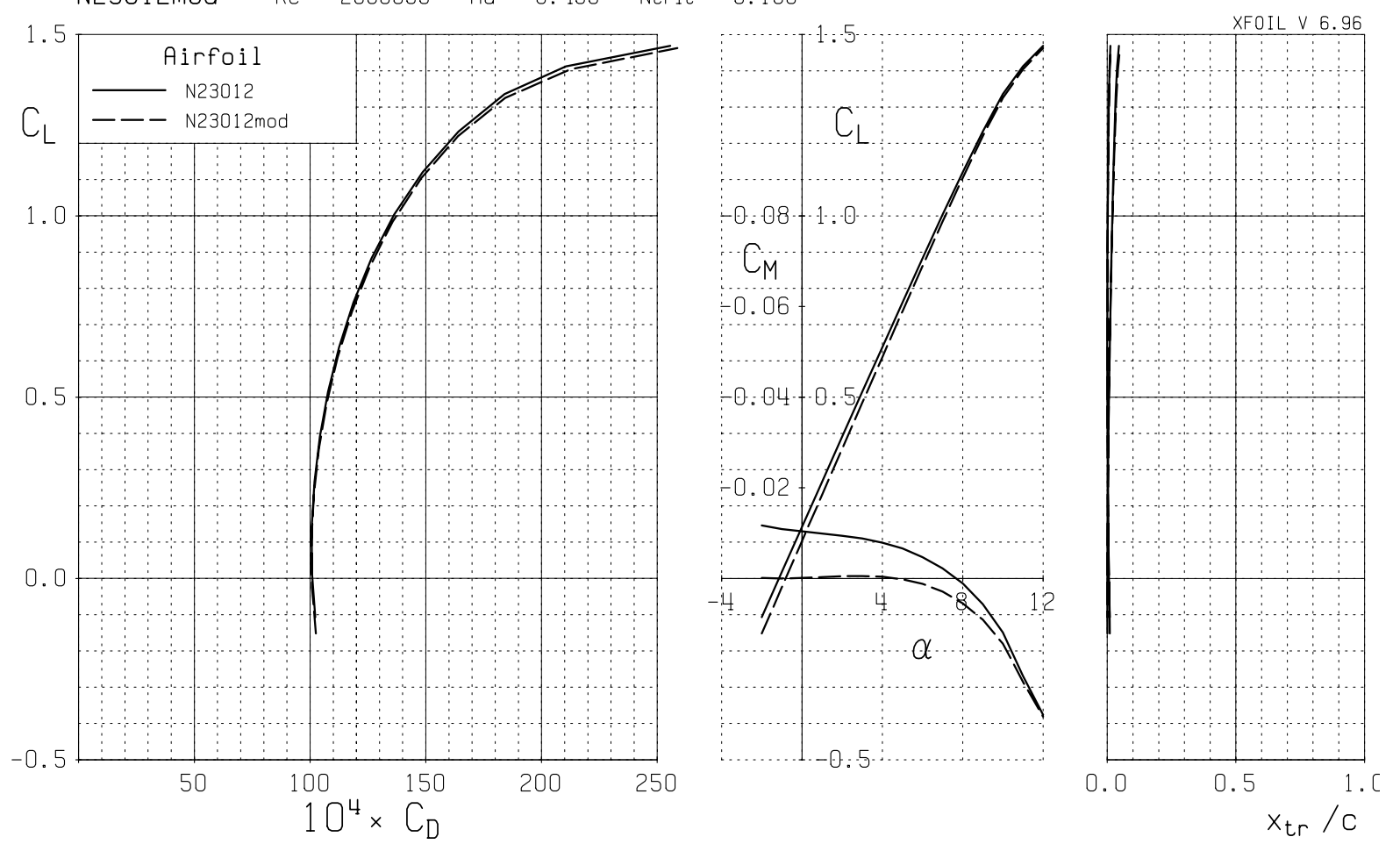

Fig 9. Distribution of pressure coefficient over original airfoil and airfoil with upper tab at zero angle of attack

\section{Conclusions}

It is possible to predict the moment coefficient of an airfoil with a trailing edge tab using coupled potential flow and the integral boundary layer method. The lower part of the tab has a cambering effect and acts at low and high angles of attack. The upper part of the tab has a decambering effect and does not act at high angles because of separation. The lift curve slope with an upper tab is therefore slightly bigger.
It is possible to control the moment coefficient of an airfoil with small modifications on the upper side near the trailing edge of the airfoil to achieve the desired value of moment.

\section{Acknowledgment}

The work has been performed under the Project HPC-EUROPA (RII3-CT-2003-506079), with the support of the European Community - Research 
Infrastructure Action under the FP6 "Structuring the European Research Area" programme.

\section{References}

1. DRELA, M. XFOIL: An analysis and design system for low Reynolds number airfoils. In Proceedings of the Conference Notre Dame, Indiana, June 5-7, 1989. New York: Springer-Verlag, 1989, p.1-12.

2. REICHERT, G., WAGNER, SN. Some aspects of the design of rotor-airfoil shapes. AGARD-CPP-111, Febr 1973. 